\title{
The Safety in Mines Research Station near Buxton.
}

\section{By Prof. H. B. Dixon, F.R.S.}

$\mathrm{I}^{\mathrm{N}}$ moving the Mines Experimental Station from Eskmeals, on the Cumberland coast, to Harpur Hill, near Buxton, the Safety in Mines Research Board has sought and has found an equally secluded site in a more accessible district. The choice of such a site in the England of to-day is no easy problem. It must be near a railway so that a siding can be run into it; it must be near a water supply; it must not be near houses or a main road, or indeed near any public path; and, if possible, it must not interfere with the amenities of the neighbourhood. Among the sandhills of Eskmeals there was seclusion enough, and the gunrange of Messrs. Vickers on the adjoining site afforded both access by rail and immunity from complaint of 'explosion-shock.' But Eskmeals had two drawbacks; it suffered from sandstorms often, and from inaccessibility at all times.

Though hidden by the folding hills, the station at Harpur Hill can be reached in about ten minutes from Buxton, whence lighting-gas and water are obtained. The site comprises more than 400 acres and gives a wide 'danger area' on either side of the steel explosion galleries. Indeed, the site of the galleries was used for testing guns and various bombs during the War; the nearest works, adjoining the site, are limestone quarries where blasting is constantly in operation.

While the scientific instruments at Eskmeals on the seashore suffered from sand and salt-spray, the high level of Harpur Hill (1200 feet above the sea) may expose the workers to greater extremes of weather. Great care, however, has been taken to afford protection to the instruments installed, and the observation-huts and experimental chambers are substantially built in concrete.

The two largest buildings on the site may bc described as the Administrative Block and the Machinery or Works Block. The first contains a row of offices for the staff, flanked at one end by a conference and lecture hall, and at the opposite end by a large laboratory and dark rooms for research work.

..Facing these offices the large works building is erected. It is rectangular in form with a central corridor-through which the light railway runs. On one side are the store-rooms, the machine shop, and the blacksmith's shop; on the other side are the battery-house, the power-house, the joiner's and the electrician's shop. 'There is also a canteen and a cook-house, and ample lavatory and bathroom accommodation for the workmen, as well as arrangements for drying clothes. From the powerhouse electric current is supplied to the various centres by two circuits-at 110 volts and 220 volts.

For the transport of heavy material a siding has been run from the High Peak line (L. M. \& S. railway), and material can be unloaded here on to a concrete platform or into the waggons of a 3-feet-gauge railway by a cross-travelling gantry crane spanning the siding and the unloading platform. The 3 -feet railway runs to the works block and to the various research buildings on the site; it also runs along the full length of the steel explosion galleries.

\section{The Explosion Galleries.}

The longer gallery, 1008 feet in length, is made up of 40 sections of mild steel tubing 4 feet in diameter and $\frac{5}{8}$-inch thick. These sections are bolted together gas-tight by means of broad flanges compressing asbestos and wire-rope packing. 
In each cabin a horizontal strip one foot wide has been removed, so that the instruments may be placed on shelves directly attached to the gallery; therefore as the gallery moves longitudinally with changes of temperature the shelves and their instruments travel with it without any strain. To read the pressures developed in the gallery the U.S. Bureau of Mines manometer has been adopted. In this instrument (shown on its shelf in Fig. 2) the pressure acts through a short tube on a cast- one side of the sensitised paper, which shows the duration and intensity of the flame, and also indicates if periodic vibrations of flame have been set up. Each manometer is separately calibrated by subjecting it to known pressures after each series of tests. The manometer records are finally read on a special drum through a low-power microscope fitted with cross-wires.

For measuring the speed of flame along the gallery, bronze plugs are arranged to screw into

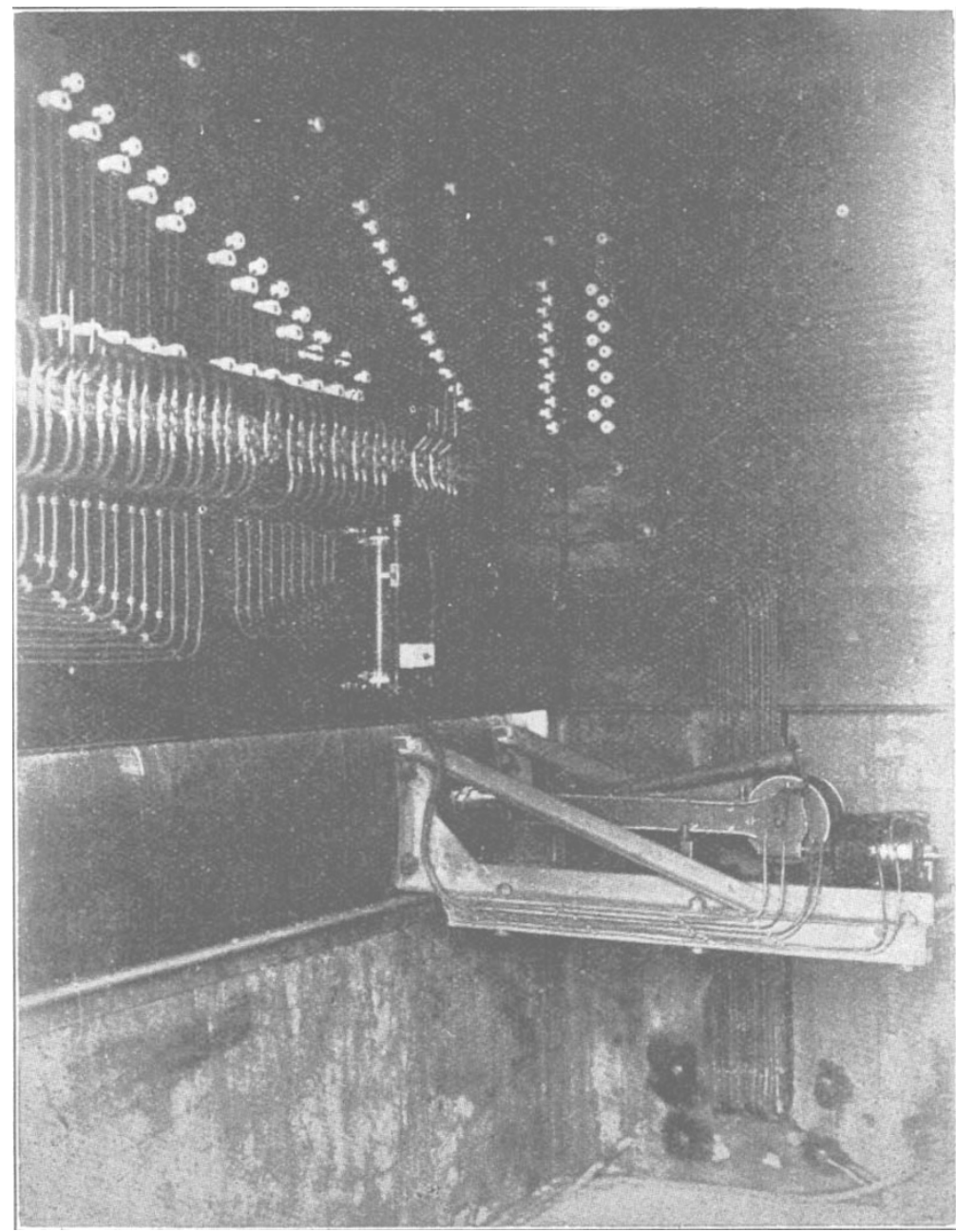

FrG, 2,-4-ft, explosion gallery. Interior of No. 5 instrument cabin, showing distribution of electric circuits and method of mounting manometer.

Keproduced from Paper No. 34 of the Safety in Mines Research Board by permission of the Controller of H.M. Stationery Office.

steel diaphragm, the movement of which is communicated to a small concave mirror of stainless steel focussing a point of light on to a rotating drum carrying sensitised paper. The arrangement is such that the movement of the diaphragm is magnified 150 times in the displacement of the light image on the drum, the specd of which is rcgistered electrically on a chronograph at the firing-station. In addition to acting as a manometer, the instrument also serves to register the passage of flame past a small thick glass window fixed in the side of the gallery. The light, when the flame illuminates the window, is focussed on the roof at intervals of 100 feet. They carry insulated steel rods 3 inches long, between which are stretched fine-gauge tin wire-to be fused by the flame, but not broken by a pressure wave. In each cabin are arranged the electrical switches to connect the flame circuit-breaker to the chronograph in the firing-station (Fig. 2).

\section{The Large and Sirall Gatleries.}

The $7 \frac{1}{2}$-feet gallery, a portion of that used at Eskmeals, has been erected for a length of 400 feet, and will be employed for demonstrations of the explodibility of pure coaldust when it is raised 
in a cloud in air and ignited. This gallery will also be used for other large-scale experiments-for example, to determine the distance to which the flame of an explosion of fire-damp is projected along a gallery. For this latter investigation 50 feet of the gallery is separated from the rest by a sliding shutter, which can be opened when the methane and air in the 50-feet chamber are thoroughly mixed. The distance travelled by the projected flame is measured by the burning of thin sticks of cordite attached to the roof every 10 feet in the open gallery beyond.

Parallel with the large gallery the 1 -foot tube, 300 feet long, is formed of sections bolted together by means of flanges-the joints being made airtight by asbestos rings. Between any two sections a steel ' restriction-ring' can be inserted in order to diminish the diameter of the tube and produce reflexions and turbulence.

The gas and air can be circulated and thoroughly mixed by means of a fan and a by-pass tube running the whole length of the gallery. This tube will be used to study the development of fire-damp explosions as the flame travels forward, both when the bore is smooth and uniform and also when the flame meets with surfaces which reflect pressure waves or cause turbulence by forcing the flamefront through smaller openings. Such restrictions, when tried on a small scale, have been shown to have remarkable effects on the travel of an explosion flame; the 1-foot tube will give the means of studying gas explosions with a larger volume of gas añ a greater 'run' of flame than is possible in a laboratory experiment.

\section{High-eXPlosives Resiarch}

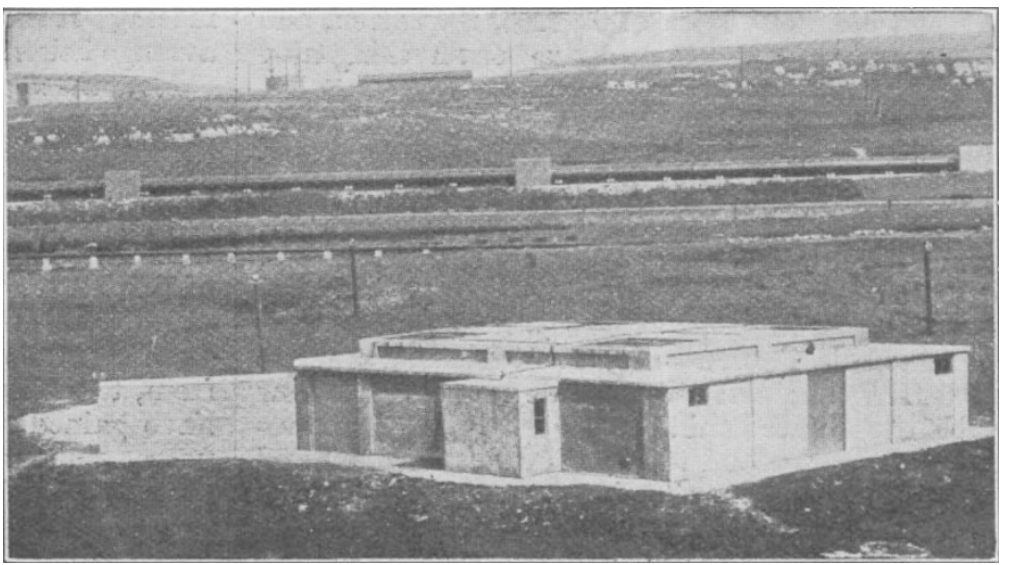

FIG. 3.-The chamber for research on gob-fires. In the backgroind is the 1-ft. gallery and beyond is a portion of the long 4-ft. gallery.

Renrodnced from Paper No 34 of the Safety in Mines Kesearch Board by permission of the Controller of H.M. Stationery Office. gas chamber, separated from the other half by an oiled-paper diaphragm, and with a central opening at the other end 12 inches in diameter. When the gun is charged it is run up on rails so as to cover this opening - making a tight joint by means of a rubber-washer fixed round the rim of the opening. The methane (or other gas) is filled into the chamber through a meter, and the gas and air are thoroughly mixed by a circulating fan and a bythick glass windows in the side of the gas-chamber from an observing station 60 feet away.

\section{Gob-fire Research Chambfr.}

Another novelty is the structure (of reinforced concrete) to be devoted to the study of gob-fires. The building consists of a central chamber 30 feet square and 8 feet high, simulating a mine goaf, with a passage 6 feet wide running round it. Between the central chamber and the passage are three openings with steel sliding doors operated pass tube. The flame can be watched through two
One of the most interesting of the new buildings is that devoted to research on the nature of the shock and flame produced by high explosives.

Plant has been installed to photograph by the Schlieren method the progress of the shock-wave through air, and also to record the movement of the flame and of the products of combustion when a high explosive is detonated in a cannon. A large concave mirror of stainless steel focusses the light from an arc lamp on to a moving film across the path of the shock-wave which refracts the beam. The movement of the pressure-wave is thus recorded in the wave-speed camera, which also serves to photograph the motion of the flame itself and of the products of combustion. The speed of the shock-wave in front of the flame, and its gradual dying down as it spreads in free air, are recorded and timed. The conditions for blanketing the flame by the burnt gases of the explosion-a sure protection against fire-damp ignition-can thus be investigated.

For the testing of explosives to be used in coalmining a steel gallery 60 feet long and 6 feet in diameter has been erected. One half of this is the from outside the building. A fan is arranged to deliver a current of air into the passage, and this can be distributed as desired through the goafchamber, into which fire-damp can also be introduced by pipes in the floor leading from a gasholder. Two control cabins are built against the outer wall, and in these the temperature of any part of the inner chamber can be read off from thermo-couples fixed in metal sheaths, and samples of air and gas can be collected from positions either in the coal heap or outside it by means of $\frac{1}{4}$-inch metal pipes protected from fouling by filter-caps fitted to the inner ends. The design of the building (which is illustrated in.Fig. 3) is to determine the limiting conditions necessary for the production and ignition of an explosive gas mixture behind a stopping, and to study the methods of sealing off a fire so as to avoid the danger of such conditions arising.

The slow-smouldering of coal-refuse in the goaf has often led to fires, difficult to extinguish, and dangerous because of the inflammable gas distilled from the heated coal. But the conditions under which such gas becomes dangerous are at present little known, and they demand skilled investigation.

No. 3022, VoL. 120] 